\title{
Tribological properties of experimental hard alloys in conditions of friction on structural steel without lubricant
}

\author{
Evgeniy V. Fominoff ${ }^{1,}$, Constantine G. Shuchev ${ }^{1}$, Igor A. Khozyaev ${ }^{1}$, Yuriy A. Tsarev ${ }^{1}$, and \\ Viktor B. Rykov ${ }^{2}$ \\ ${ }^{1}$ Don State Technical University, 344000 Rostov-on-Don Gagarina sqr. 1, Russia \\ ${ }^{2}$ State Scientific Establishment "Agriculture research center "Donskoy", North Caucasus Institute of \\ Mechanization and Electrification of Agriculture, 347740 Zernograd, Russia
}

\begin{abstract}
Tribological properties of the experimental grades of high entropy hard alloys with modified binding phase on cobalt, which are characterized by minimal value of absolute t.m.f. to carbide phase, were experimentally investigated. It was established experimentally that new grades obtain better friction characteristics in comparison with the base alloy grade VK8 because friction processes of these materials in contact with structural steels are characterized by lower friction forces and lower temperatures in the friction zones. The 'third body' which is thicker than for the base alloy grade VK8, obtains a positive gradient of mechanical properties in friction zone, has a shielding effect, reduces the rate of generation of adhesive joints (welding bridges), and, perhaps, performs the role of dry lubrication.
\end{abstract}

\section{Introduction}

Edge cutting tools (CT) and their reliability play an important role in ensuring the effectiveness of the metalworking. High cutting speeds characteristic for modern high performance machine-tools with CNC lead to increasing of application scope of CT fitted with inserts made of cemented carbides or hard alloys (HA). Cemented carbide tools in these conditions operate at temperatures close to the limit of thermal resistance and wear processes are, mostly, of diffusion and oxidizing types. Currently one of the major trends of increasing performance characteristics of HA grades is modification of their carbide and binding phases in order to save scarce tungsten and cobalt without compromising their physical-mechanical and operational characteristics. One of the most important operational characteristics of cutting tool materials is their wear resistance. Evaluation of the wear intensity rates can be obtained on the basis of entropy balance equations indicating that wear during friction and cutting processes will be less for materials with the largest value of entropy S [1]. The rate of the oxide film growth is determined by the expression [2]:

\footnotetext{
*Corresponding author: fominoff83@mail.ru
} 


$$
\frac{d h}{d \tau}=\frac{1}{F_{c} \cdot \sqrt{2 \tau}} \cdot \sqrt{\sum_{l}^{k}\left(\frac{M_{i}}{\gamma_{i} \cdot m_{i} \cdot n_{i}}\right) \cdot \eta_{i} \cdot \sum_{l}^{k}\left(\frac{H_{i}-T \cdot S_{i}}{m_{i} \cdot n_{i} \cdot \rho_{i}}\right) \cdot \mu_{i}}
$$

where $F_{c}$ - the Faraday constant; $M_{i}$ - molar mass; $\gamma_{i}$ - the density of material; $m_{i}-$ the number of moles; $n_{i}$ - valence; $\rho_{i}$ - specific resistivity; $\eta_{i}$ - mass fraction of oxide of the (i) grade; $H_{i}, S_{i}$ - enthalpy and entropy of formation of oxide of the (i) grade accordingly; $\mu_{i}$ - the percentage of oxide of the (i) grade in the oxide layer, $\tau$ - the time.

From the expression (1) it follows that the speed of oxide film growth will be lower for the high entropy grades of HA because high value of $S_{i}$ reduces the intensity of oxidative wear.

To evaluate the wear resistance of CT materials the structurally sensitive microparameter - the absolute t.m.f. of the material $E$ also may be used, which is related to the entropy according to the following expression $[3,4]$ :

$$
E=-\frac{\Delta H-T \cdot \Delta S}{n_{e} \cdot F_{c}}
$$

where $n_{e}$ - the number of electrons.

From (2) it should be that high entropy value of the material corresponds to the lower value of its absolute t.m.f. $E$ by assuming that the process takes place at constant enthalpy $\Delta H$ and temperature $T$. Therefore, when designing HA you should strive to create materials with high entropy and low absolute (or relative) t.m.f. [3].

Hard alloys on the structure are of polyphase type compounds, binder also may be of multiphase type, especially if steels are used as binder. So the surface of HA element may be of "spotty" type and those "spots" are characterized by different work of electrons release, which parameter determines the magnitude and sign of t.m.f. of the element as a whole [1]. Consequently, the composition of carbide and binding phases must be chosen so that the difference of their absolute values of t.m.f. was minimal (ideally $\Delta E=0$ ) or binder towards carbide phase should be positive.

At the Chair "Metal-cutting machines and tools" of Don State Technical University experimental grades of HA based on WC carbide phase with modified binder having the lowest and positive values of absolute t.m.f. were developed [3].

The best performance characteristics while turning structural steel in comparison with the base alloy VK8 [3] showed samples, whose composition and properties are presented in table 1 .

Table 1. Composition and physico-mechanical properties of experimental hard alloys grades [3]

\begin{tabular}{|c|c|c|c|c|}
\hline Grade & Composition & $\begin{array}{c}\text { Entropy } \boldsymbol{S}, \\
\mathbf{J} / \mathbf{m o l} \mathbf{K}\end{array}$ & $\begin{array}{c}\text { Absolute } \\
\text { t.m.f. } \\
\boldsymbol{E}, \mathbf{m V}\end{array}$ & $\begin{array}{c}\text { Hardness, } \\
\boldsymbol{H R} \boldsymbol{A}\end{array}$ \\
\hline 2.21 & $\begin{array}{c}5,4 \% \mathrm{Co}+1,43 \% \mathrm{Fe} \\
+0,82 \% \mathrm{Cu}+92,45 \mathrm{WC}\end{array}$ & 35,18 & 3,75 & 90,5 \\
\hline 2.22 & $\begin{array}{c}5,65 \% \mathrm{Co}+1,8 \% \mathrm{Mo}+0,6 \% \\
\mathrm{Ti}+91,95 \% \mathrm{WC}\end{array}$ & 35,26 & 3,32 & 91,8 \\
\hline 2.23 & $\begin{array}{c}5,1 \% \mathrm{Co}+2,7 \% \mathrm{Mo}+ \\
0,61 \% \mathrm{Ti}+91,59 \% \mathrm{WC}\end{array}$ & 35,16 & 4,5 & 91,5 \\
\hline $\begin{array}{c}\text { VK8 } \\
\text { (basic) }\end{array}$ & $\begin{array}{c}{[7,5-8] \% \mathrm{Co} ;<0,3 \% \mathrm{Fe} ;} \\
<0,5 \% \mathrm{O}_{2} ; 92,0 \% \mathrm{WC}\end{array}$ & 35,00 & 9,8 & 87,25 \\
\hline
\end{tabular}


High resistance to gas corrosion of test specimens was established by heating in a muffle furnace at a temperature in the order of $500{ }^{\circ} \mathrm{C}$. However, at lower temperatures $\left(300^{\circ} \mathrm{C}\right)$ experimental HA grades were slightly inferior to basic alloy VK8 [3]. It should be borne in mind that chemical reactions may proceed differently under static conditions and conditions of friction when surfaces of contacting bodies are mechanically activated [5-7]. The features of self-organized dissipative structures generated on contacting surfaces during friction as well as their rheological properties also can influence wear resistance of HA.

\section{The purpose of the work}

The purpose of this work consists in the study of tribological characteristics of experimental grades of high entropy HA, exploring features of formation and self-organization resulting from the friction and generation of dissipative structures on contact surfaces and their comparison with similar indicators for the base HA grade VK8.

\section{Experimental part}

Tribological tests of square samples of HA $(5 \times 5 \mathrm{~mm}, \mathrm{Ra}=0,1-0,14 \mu \mathrm{m})$ were conducted on tribotester T-11 (Poland), which implements a scheme of friction "pin on disk"; measured and saved parameters were friction force $F$, the offset of the indenter (pin) relative to the rider (disk) $\Delta$ and the time of the experiment $\tau$. Material of disk - structural steel 30HGSA, $\mathrm{Ra}=0.17-0.15 \mu \mathrm{m}$, HRC $35 \ldots 38$. Measuring of the temperatures in adjacent to the contact areas was produced by a non-contact method using digital thermal imager Testo 868. Roughness of pins and disks was measured using the profilograph - profilometer Abris-PM7.

\section{Results and discussion}

It was found that experimental grades have better frictional characteristics in comparison with the base alloy VK8, because friction process proceeded for them with less friction coefficients and temperatures in all investigated range of sliding speeds (fig. 1.2). Of course, the real temperatures on contact surfaces differ from those shown on the chart, however, the temperature field images obtained by digital thermal imager Testo 868 provide sufficient information for comparison of different grades of HA.

a)

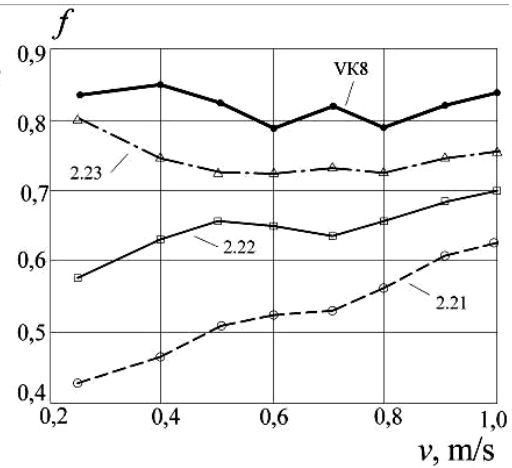

b)

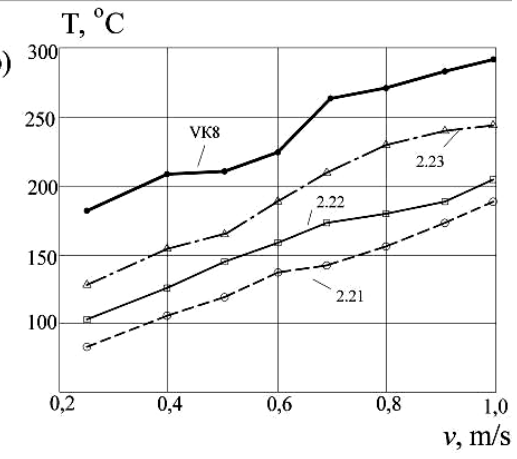

Fig. 1. Friction coefficients (a) and contact temperatures (b) for different grades of hard alloys $(\mathrm{P}=3.2 \mathrm{MPa})$. 
The process of 'a third body' formation was investigated by the offset of the indenter (pin) relative to the rider (disk) $\Delta$ during friction. Characteristic curves are given in Fig. 3.

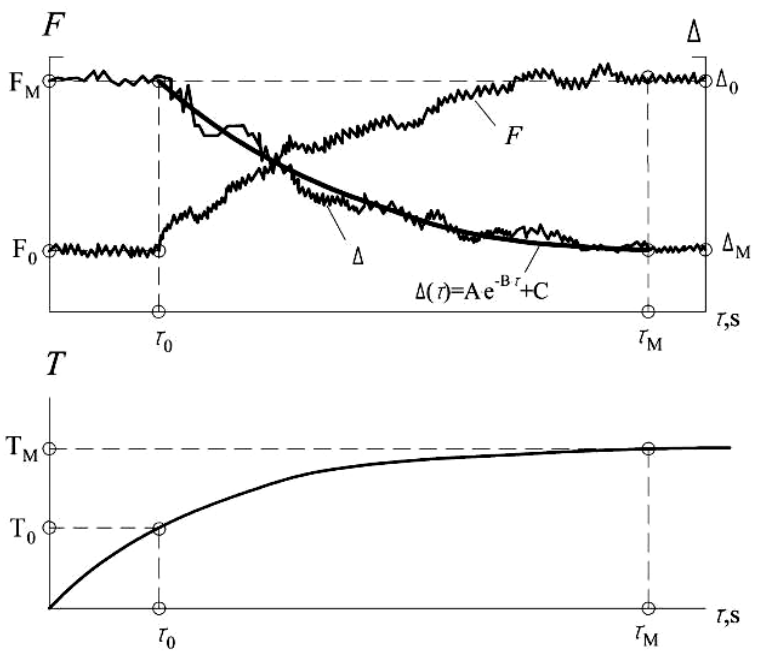

Fig. 2. Characteristic curves for indenter offset $\Delta$, friction force $F$ and temperature $T$ during the process of 'a third body' formation.

The increasing of intermediate 'third body' thickness during friction leads to increasing of indenter offset from starting level $\Delta_{0}$ to relatively stable level $\Delta_{\mathrm{M}}$ which corresponds to maximum possible value of intermediate 'third body' thickness attainable after period of time $\tau_{\mathrm{M}}-\tau_{0}$. The process is accompanied by an increase in friction force and temperature which may be explained by the actual contact area increasing during formation of the 'third body'.

It should be noted that the dependence of offset of indenter during friction $\Delta(\tau)$ may be approximated by exponential function of the form:

$$
\Delta(\tau)=A \cdot e^{-B \cdot \tau}+C
$$

where $A, B, C$ - coefficients, which values may be estimated on the base of $\Delta(\tau)$ experimental realizations processing.

Thus, the trend of the of oxide films growth rate, described by the decreasing function (1), is consistent with the trend of regression function (3), describing the process of the 'third body' formation. The both processes are characterized by rapid growth at the beginning followed by slowing down when the process parameters stabilize their values. However, unlike (1), the function (3) may be used as a mathematical model to describe the complex dynamic processes of formation/destruction of dissipative structures (the 'third bodies') and their self-organization during friction.

It was proposed the process of the 'third body' formation during friction for HA having various entropy levels characterize in the first approximation by the two quantitative indicators. The first indicator is the maximum possible value of the 'third body' thickness under specified conditions $\Delta \mathrm{h}$ :

$$
\Delta h=\left|\Delta_{M}-\Delta_{0}\right|
$$

In the initial period of the friction process (running-up period) curves $\Delta(\tau)$ and $F(\tau)$ are of non-corresponding and somewhat chaotic type (fig. 3). Such chaotic variations can be 
attributed to many random factors: mechanical smoothing of initial roughnesses, oxidation of juvenile surfaces, formation and destruction of initial adhesion links, wear particles presence in the gap between samples, vibrations, etc. This happens until the level of thermo-mechanical effects reaches some critical value $\left(T_{0}, F_{0}\right)$ sufficient to activate the processes of self-organization and dissipative structures formation in the friction zone. After this period curves $\Delta(\tau)$ and $F(\tau)$ are of corresponding type and the maximum possible (or 'guaranteed') value of the 'third body' thickness under specified conditions $\Delta \mathrm{h}$ can be measured according the expression (4).

The second indicator represents the amount by which the rate of formation of the third body is more than the rate of its destruction:

$$
\omega=\frac{\left|\Delta_{M}-\Delta_{0}\right|}{\tau_{M}-\tau_{0}}
$$

This parameter may be named as the speed of the of the 'third body' formation $\omega$.

Experimentally estimated values of these parameters (fig. 4) are higher for experimental grades of HA. This fact may be explained as due to their lesser resistance to gas corrosion relative to basic grade VK8 observed in static conditions at recorded values of temperatures in the friction zone [3].

On the other hand, the process of the 'third body' formation for the studied materials depends not only on the speed of gas corrosion, described by the expression (1), but also on many other factors. Produced during friction dissipative structures for experimental grades may have greater resistance to abrasion or a higher degree of supramolecular selforganization. Roughnesses of contact surfaces after friction as well as the characteristics of the supporting profile curves suggest the elastic type of contact, therefore, recorded friction force values were formed mainly due to adhesion effects [5-7]. The observed large maximum possible thicknesses of the 'third body' during friction for investigated experimental grades of HA makes it possible to ensure a positive gradient of mechanical properties and creates a shielding effect for friction surfaces, making the process of formation and destruction of adhesive joints (welding bridges) less intense.

High hardness of experimental grades (table 1, column 5) contributes to a better retention of protective films on the surfaces of the samples [5-7]. A lower level of adhesion effects on the contacting surfaces was also shown by the value of longitudinal roughness on tracks of counter bodies [5]. If after friction for experimental grades of HA longitudinal roughness values were $\mathrm{Ra}=15-30 \mu \mathrm{m}$, for basic grade VK8 it exceeded $40 \mu \mathrm{m}$.
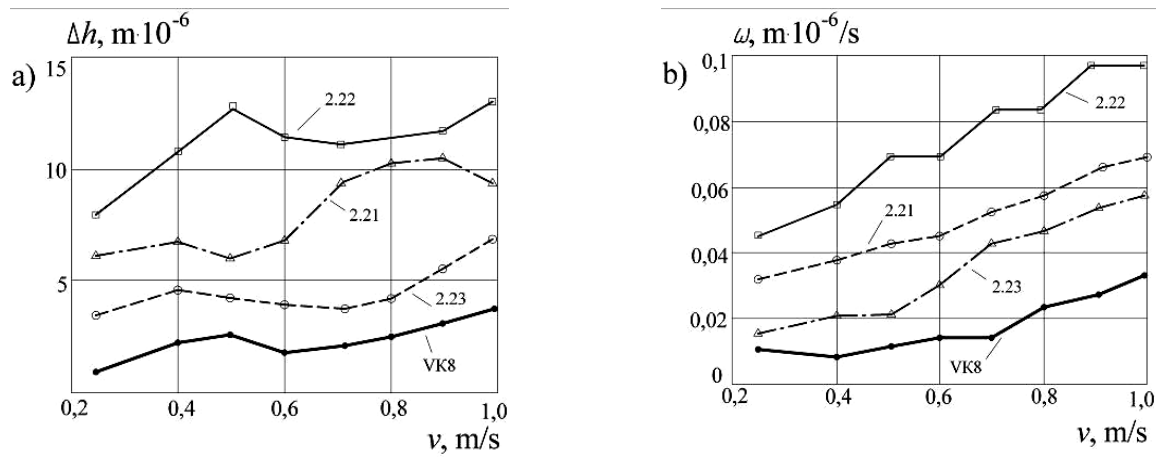

Fig. 3. Characteristics of the process of the 'third body' formation for various grades of HA ( $\mathrm{P}=3.2 \mathrm{MPa})$ : a) $\Delta h(\mu \mathrm{m})$; b) $\omega(\mu \mathrm{m})$. 
Thus, despite the possible lower resistance to gas corrosion observed in static conditions at temperatures within the range $300{ }^{\circ} \mathrm{C}[3,8]$, high wear resistance during friction and cutting processes of investigated experimental grades of HA may be attributed to reduced intensities of adhesion wear.

\section{Conclusion}

Tribological properties of experimental grades of HA with a modified cobalt binder were investigated which grades previously found a significant increase in wear resistance when cutting in comparison with the base alloy VK8. Friction process for these materials is characterized by low friction and lower temperature in the friction zone, because of the peculiarities of formation and self-organization, as well as rheological properties of the 'third body'. The generated during friction intermediate layer (the 'third body') was thicker for experimental grades than for VK8 thus providing shielding effect by reducing the adhesive bonding and possibly acted as a dry lubricant.

\section{References}

1. A. A. Ryzhkin, Synergetics of cutting tool materials wear processes, triboelectric aspect (Izd. tsentr DSTU, Rostov-on-Don, 2004) [in Russian]

2. A. A. Ryzhkin, Mehanica i tribologia tranportnih system, 195 (2011) [in Russian]

3. A. A. Ryzhkin, V. E. Burlakova, D.V. Moiseev, E.V. Fominoff, Journal of Friction and Wear, E 37, 1 (2016)

4. A. A. Ryhkin, E.V. Fominoff, U.A.Torop, Vestnik DGTU J., 2 (2017) [in Russian]

5. I. V. Kregelskiy et. al., Basis of calculation for friction and wear (Mashinostroenie, Moskva, 1977) [in Russian]

6. P. J. Blau, Friction science and technology: from concepts to applications (Taylor\&Fransis Group LLC, 2009)

7. K. V. Frolov, Modern tribology (LKI, Moscow, 2008) [in Russian]

8. A. A. Ryzhkin, V. E. Burlakova, Sbornik nauchnih statey po materialam 13-oy Mezhdunarodnoy nauchno-prakticheskoy konferentsii, 4 (2015) [in Russian] 